\title{
Investigating the interpretation and implementation of policies that guide the teaching of reading in the Foundation Phase
}

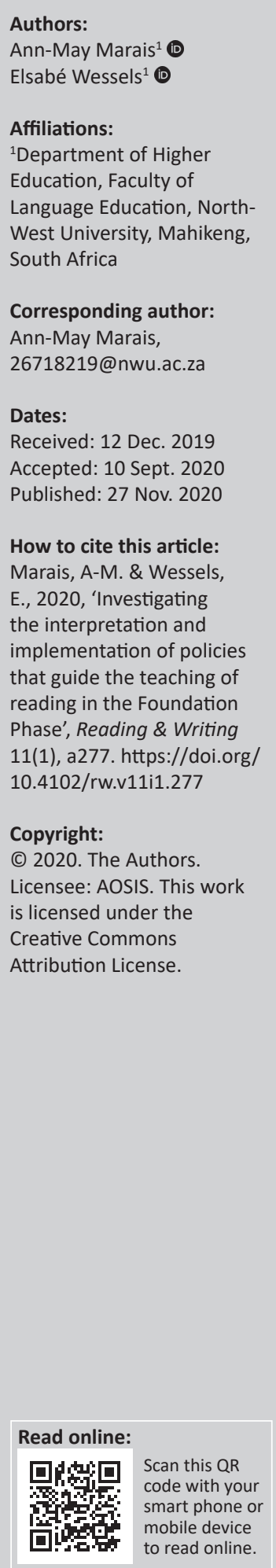

Authors:

Ann-May Marais ${ }^{1}$ Language Education, NorthWest University, Mahikeng,

Ann-May Marais,

Dates:

Received: 12 Dec. 2019

Accepted: 10 Sept. 2020

implementation of policies

that guide the teaching of

\section{(c) 2020. The Authors.}

is licensed under the

Creative Commons

Attribution License.

mobile device

to read online.
Background: There is growing international awareness of the dividends of early reading success and the consequences of early reading failure. Many studies have shown that the educational achievement of South African learners is unacceptably poor. There are shortcomings in the curriculum for English home language (EHL) which could be the reason for educators' uncertainties and frustration with the teaching of reading.

Objectives: To identify policies that guide the teaching of reading and to investigate the management of their interpretation and implementation.

Method: A qualitative case study design was employed, underpinned by the sense-making theory which was used as a theoretical framework. Three primary schools in the Lichtenburg circuit were selected as study sites. Participants were selected purposively and data generation methods included document analysis, observations and interviews. Inductive data analysis was applied through the identification of patterns, categories and themes.

Results: The results indicate that the EHL curriculum document is the only policy document that teachers in this study used as a guideline for the teaching of reading in the Foundation Phase. However, this document lacks explicit guidance on how reading should be taught.

Conclusion: The main policy that guides the teaching of reading in the Foundation Phase is the EHL curriculum. However, participants do not always understand the stipulations of this document and make partial use of the guidelines because they do not know how to interpret them. The curriculum lacks step-by-step guidelines on teaching activities for reading. Thus, we suggest that professional development should be based on the needs of the educators.

Keywords: Curriculum and Assessment Policy Statement; English Home Language curriculum; interpretation; implementation; policy; reading policies; reading; teaching reading; Foundation Phase.

\section{Introduction}

There is growing international awareness of the dividends of early reading success and the consequences of early reading failure. A number of studies have shown in recent years that the educational achievement of learners in South African schools is unacceptably poor (Buhlungu et al. 2007; Wium \& Louw 2011). The 2014 Annual National Assessment (ANA) results indicated an average of 56\% for English home language (EHL) for South African learners in Grade 3, while the ANA results of 2015 clearly indicated that learners struggle to read with comprehension (Van der Berg 2015). Van der Merwe (2011) has levelled the criticism that educators lack depth and interest and do not have the knowledge required to teach reading. The former minister of education, Pandor (2008), noted that educators must receive support to implement the different reading policies, starting with the knowledge and skills that are necessary for teaching reading. The Department of Education (DoE) also stated that educators do not know how to interpret and implement the different reading policies so that they provide explicit instruction to learners (Department of Basic Education [DBE] 2008). Proper interpretation and implementation of reading policies is essential for successful teaching. The purpose of this article, therefore, is to discuss how educators interpret and implement reading policies in the Foundation Phase.

The focus of this article is on reading and reading policies, and how educators interpret and implement these policies in the Foundation Phase. In recent years, the educational achievement of learners in South African schools has been reported as unacceptably poor (Wium \& Louw 2011). 
In an attempt to provide educators in the Foundation Phase with guidance to assist beginner readers, the Department of Basic Education (DBE), provincial departments and schools have several policies and guidelines in place, which are relevant to teaching reading. These policies include the Curriculum and Assessment Policy Statement (CAPS) EHL (DBE 2011) (with supplementary documents like the programme of assessment, moderation reports, intervention, timetable, reading and phonics programme, annual teaching plans [ATPs], lesson plans and examples of worksheets, monitor and control reports and planning). Other policies include the National Reading Programme for Grades 1 to 3 (DBE 2013), area office policies, subject policies and internal school policies. In total there were at least five official policy documents to address the teaching of language, including reading. In addition, the policies provide guidance with regards to learner support when learners do not meet the appropriate reading levels.

The curriculum is defined and used according to Cross and Conn-Powers's (2014) definition that a curriculum is a big plan that connects all the content areas together in an integrated structure. In addition, the National Reading Panel (2000) identified the five principal components of reading instruction. These are phoneme awareness, phonics, reading fluency and text comprehension (Cross \& Conn-Powers 2014). The Wits Education Policy Unit (2005) comments that educators have poor knowledge, do not understand the content (subject), and make mistakes with concepts in their lesson plans. Schools must take curriculum planning, interpretation and implementation very seriously because the curriculum gives guidelines about what must be taught in class and what must be covered on a term-by-term basis (Wits Education Policy Unit 2005). Wessels (2011) points out that planning includes implementation of the policy, the learning outcomes and activities that are aligned with the outcomes, as well as the learning and teaching support material (LTSM). Education reading policies are in place to assist educators in teaching reading in a comprehensive manner (Wessels 2011). However, Nehal (2013) states that few studies deal directly with this issue as it manifests in the Foundation Phase. Educators must know and be able to apply a variety of teaching pedagogies when they teach reading. Educators know about the different methods and pedagogies mentioned in the policies but have no idea how to interpret and use them in their teaching (Nehal 2013).

\section{Theoretical framework}

This study was underpinned by the sense-making theory which was used as a theoretical framework. According to Root (2013) the sense-making theory describes processes of how people think about certain things, how they understand them and how the meaning they gain leads to action or inaction. The sense-making theory is used to explain the experiences of interpretation, implementation and management of reading policies (Root 2013). Dorner (2012) asserts that studies in sense-making focus on what policy means, not only from knowledge, beliefs and attitudes but from the context and the learning situation and interaction that happens in that context. Coburn (2001) notes that educators play a crucial role in the sense-making process as they mould the policy in their professional teaching. The process contributes to the educators' understanding and knowledge of the relationship between policy and classroom teaching (Coburn 2001).

The appropriate interpretation and implementation of reading policies are essential for successful teaching. The main aim of this research is to determine how educators interpret, implement and manage reading policies for the Foundation Phase. The following research questions guide this article: how are Foundation Phase reading policies interpreted, implemented and managed in the Foundation Phase? The main research question divided into the following sub-questions: firstly, what policies and documents guide the teaching of reading in the Foundation Phase? Secondly, how do educators interpret, manage and implement these policies?

\section{Research methods and design Research design}

For this article, we used a qualitative mode of inquiry. Adam (2014) states that qualitative researchers study the phenomenon in its natural setting, with the intention to dig deeper into the significance that the phenomenon of the research ascribes to the topic under research. Qualitative research provides information about the human side of an issue, such as social justice, beliefs, opinions, emotions and relationships of individuals. An advantage of the qualitative approach is to provide in-depth information and a deeper understanding of the phenomenon (Adam 2014). The multiple case study design:

... explores a real-life, contemporary bounded system (a case) or multiple bonded systems (cases) over time, through detailed, in-depth data collection involving multiple sources of information and reports a case description and case themes. (Creswell 2013:97)

In this project, we used a multiple case study to gain a broader understanding of the findings and to compare the case studies with each other to see the similarities and differences. The multiple case study allowed a wider exploration of the research questions and enabled the development of a more convincing argument.

\section{Research paradigm and philosophical orientation}

A paradigm provides a philosophical foundation, which includes a philosophical and analytical lens. The paradigm that we have chosen was drawn from an interpretivist point of departure. Maree (ed. 2009) states that interpretivism is about a perspective on a specific situation. It is a way to analyse a situation, to gain insight into certain people or a group of people and to attach meaning to the situation. Deeper meaning can be explored, the situation can be better 
understood and thereafter recommendations can be made (ed. Maree 2009). Reality must not be conflated with our experiences, but the conflation of ontology (what is) from epistemology (what can be known) is termed by Bhaskar (1978:16) as the 'epistemic fallacy'. Zuber-Skerritt and Wood (2019) confirm that conflation can be explained as ontology (an assumption about the nature of reality). This stipulates the form and nature of reality and what can be identified about it as epistemology (which refers to the nature of human knowledge and understanding or knowing about this knowledge) and axiology (which refers to beliefs, values and worldviews). As a result of axiology, researchers should include their cultural background, social justice and personal values in the research process (Boughey 2012). For this study, we believe that the link between the worldview and paradigm is that we learn from each other and how we see the world. Indeed, the worldview and paradigm influence our thinking and behaviour through the different lenses, but because we shall have a better understanding of the phenomenon, everyone has something to contribute to the value of the study to see the bigger picture (Wood 2020).

\section{Setting}

Three primary schools in one of the circuits in the North West province of South Africa were identified. The selected schools are the only three schools in this circuit that use English as their language of learning and teaching (LoLT). Each school has one class per grade. The schools are government schools and have more or less the same number of learners, which is about 300 . Each class has between 45 and 60 learners. The research sites for this research were suitable because the sites provided the opportunity to select different educators from different schools as potential participants. The three English primary schools were deemed sufficient for in-depth information and as suitable for a qualitative case-study design.

\section{Participants}

Participants were chosen using purposive sampling. According to McMillan and Schumacher (2010), purposive sampling is based on the awareness of the researcher, who in this case chose the participants purposively so that they either reflect essential characteristics of the population or are familiar with the phenomenon. Jackson (2003:19) defines sampling as 'decisions about where to conduct the research and whom to involve, an essential part of the research process', and adds that sampling 'usually involves people and settings as well as events and processes'. The logic of purposeful sampling is that a case study is in depth and this gives many insights into the topic (Mouton 2003:135). The sample allowed different perspectives on the interpretation and implementation of reading policies. The participants in this study were all Foundation Phase educators from the three identified schools in a circuit in the North West province. There was only one class per grade from Grade 1 to Grade 3 in the Foundation Phase in each school. This means that we interviewed all the educators from the school who taught Foundation Phase (Grade 1 to Grade 3). The group of participants in this study was nine educators, one head of department (HoD), one principal and two subject advisors. In total, the number was 13 educators involved in the Foundation Phase. One educator from each grade from Grade 1 to Grade 3 in the Foundation Phase in each school, the $\mathrm{HoD}$ of the Foundation Phase (one HoD per school), one principal per school and two subject specialists for EHL in the circuit.

\section{Data generation strategies}

The data generation methods had to be in line with qualitative research, therefore document analysis, observations, field notes and interviews were used.

\section{Document analysis}

Documents of all types can help to uncover meaning, develop understanding and discover insights relevant to the research problem (Wessels 2011). Adam (2014) notes that document analysis is often used in combination with other qualitative research methods as a means of triangulation, to provide a confluence of evidence that breeds credibility (Adam 2014). Therefore, triangulation ensures the credibility of this qualitative research project. The data received from the different sources - document analyses, observations, interviews and field notes - were used together to add credibility, objectivity and validity to the interpretation of the data. All DBE documents and policies, including the internal school reading policies and documents, were looked at. The part of the educators' language file dedicated to reading was investigated to establish if the work done in the schools was according to prescribed policies. The programme of assessment, work schedules, a reading programme, formal tasks (pre- and post-moderation), a list of LTSM, a timetable, daily or weekly preparations, minutes of meetings and interventions were looked at. The document analysis offered information about the educators' application of policies, about what kind of policies and documents Foundation Phase educators use with regard to reading, as well as information about how the educators interpret and implement these policies and documents.

\section{Observations}

The observations took place in a natural setting in the relevant classrooms. An observation schedule was drawn up to observe the teaching of reading in the classroom. The time allocation was arranged so that observation could take place during the language periods on the timetable and the dates of site visits were scheduled according to the participants' convenience, the school's schedule, and the researcher's availability. The researcher visited each school for 2 days. During these visits, the Grade 1, 2 and 3 educators' teaching practices with regard to reading were observed to establish how these practices align with guidelines in the relevant policies and documents. The classroom was observed during the language period when reading was taught. The observations included the classroom environment (posters on the wall, language in the class) and resources available (big books, reading books, flashcards and other appropriate LTSM). The participants were also observed to 
determine whether they made use of different kinds of reading and assessment strategies. These observations informed the study on whether the educator interpreted and implemented the reading policies and documents that guide reading in the Foundation Phase. The researcher observed and took detailed field notes during the related lessons, in particular the reading lessons.

\section{Interviews}

Bourne (2003:19) notes that 'interviews allow the interviewer to probe areas of interest as they arise during the interview'. It establishes a confidential relationship, making it an appropriate method to obtain information from an interviewee. The natural setting was the classrooms with the aim being to obtain first-hand information about the activities that take place in these environments. Interviews were conducted with educators from Grades 1, 2 and 3. The interviews took place individually and face-to-face. The interviews were semi-structured and where the questions were predetermined, the interviewer allowed flexibility. Flexibility ensured that the participants could talk freely as the interviewer did not stick rigidly to the predetermined questions. A semi-structured interview with open-ended questions was chosen to create an opportunity to probe further to allow more clarifying, probing and cross-checking questions. An interview guide was used to guide the researcher and to probe some areas of interest and an appropriate method to lead the interview procedure. The recording of the interview data took place by means of note taking and audio recording as recommended by Huberman and Miles (2002) and De Vos et al. (2006).

Furthermore, the interviews were conducted privately in the appropriate classrooms. Interviews with the educators took place after observation. The observations allowed for 'reading between the lines' and the collection of data that would otherwise have been lost. All educators elaborated in detail on each question, irrespective of whether it would expose limitations in their schools or HoD. The interview, even if it is time-consuming (an hour per participant), is one of the most critical data generation tools as it provides in-depth information and provides for follow-up questions if the initial question allows (McKeown \& Beck 2006:299).

\section{Field notes}

The researcher did not only record what was seen and heard but also reflected on additional activities like how the learners responded to the teaching and whether the learners paid attention during class visits. The researcher made use of field notes to document observations and preliminary interpretations to follow up on during the interviews (McMillan \& Schumacher 2010).

\section{Data analysis}

Inductive analysis was used in this study (McMillan \& Schumacher 2010). Creswell (2014) describes inductive analysis as follows: 'qualitative researchers build their patterns, categories, and themes from the bottom up, by organizing the data into increasingly more abstract units of information'. This inductive process illustrates working back and forth between the themes and database until a comprehensive set of themes has been established. Information from the observations and field notes, documents and interview transcripts was utilised to gain a better understanding. A systematic process was followed to analyse data by recording data, transcribing data and coding data into themes and categories. In the case of data generation through interviews, this meant that once the interviews had been completed, the data were analysed. The interviews were audio recorded and transcribed verbatim (Creswell 2014). The study followed a systematic process to analyse data by recording data, transcribing data and coding data into themes and categories. Once the data had been coded, the data were organised according to the themes and categories.

In accordance with standard, accepted principles of ethical research procedures, all relevant authorities were contacted and the research took place with the informed consent of all participants. All participants took part in the research voluntarily and they could withdraw at any time. In addition, the individual's right to privacy was respected. As stressed in the consent forms, all participants took part in the research project voluntarily and the privacy of the individual and school was respected. Confidentiality and anonymity were maintained at all times. The researcher also maintained academic objectivity at all times.

Trustworthiness was guided by Bush (2012:81-86), who points out that different aspects should be considered when investigating the reliability, validity and triangulation of a qualitative study. Furthermore, triangulation means that the researcher compares many kinds of evidence to determine the accuracy of the phenomena, in other words, to cross-check the data to establish trustworthiness. Wood (2019) suggests that it is essential that the research should be confirmable. The extent to which the researcher can support the research, contributes to establishing whether the research is credible. The legitimacy of the interview was assured with a clear conceptualisation, the purposeful design of an interview schedule, as well as a set plan or protocol to conduct the interview.

\section{Ethical consideration}

Permission to conduct the research was obtained from the authorities and ethical clearance was granted by the NWU Institutional Research Ethics Regulatory Committee (IRERC) NWU-00386-16-A9, which attested that the study adhered to the requirements for informed, voluntary consent, confidentiality and measures to ensure no harm was caused to participants.

\section{Discussion of the results}

Three primary schools in one of the circuits in the North West province of South Africa were part of the project. These schools have English as their LoLT. All of the participating 
educators had the formal qualifications needed to teach reading in the Foundation Phase, except for one participant at School A.

School A is a full-service school situated in a quiet suburban part of Lichtenburg. It is located in an area that was formerly exclusive to whites and was the only English medium school in the old dispensation. School A has 320 learners and 14 staff members. The staff consists of the principal, 10 educators teaching from Grade $\mathrm{R}$ to Grade 7, a Grade $\mathrm{R}$ assistant, a learner support educator and the administrative assistant (AA).

School B is situated in a suburban area outside of town. School $B$ has 271 learners and is a full-service school. The staff consists of nine staff members: the principal, eight educators teaching from Grade 1 to Grade 7 and the AA.

School C is situated in a suburban area of Lichtenburg. School $C$ has 342 learners and is a full-service school. The staff consists of 12 members: a principal, 10 educators teaching Grade R to Grade 7, a Grade R assistant and two AAs.

Each school has one class per grade. The schools are government schools and have more or less the same number of learners, which is about 300 .

The data and discussion thereof will follow subsequently. Two main themes with sub-themes were identified. The first theme involved the interpretation of policies and documents that guide the teaching of reading in the Foundation Phase. Three sub-themes were identified; these are: reading policies used in the Foundation Phase, weaknesses of the CAPS EHL document (DBE 2011), analysis and interpretation of educators' EHL files. The second theme entailed the implementation of policy documents, and two sub-themes were identified: skills and knowledge educators need to implement reading policies and other documents, as well as teaching methods and strategies educators use to teach reading.

\section{Theme 1: Interpretation of policies and documents that guide the teaching of reading in the Foundation Phase}

With regard to reading policies used in the Foundation Phase, the participants indicated that the CAPS EHL document (DBE 2011) was the primary policy applied in the classrooms to guide the teaching of reading in the Foundation Phase. This was confirmed during the classroom observations, as educators were mostly using the CAPS EHL document in class. Although there were other support documents like a programme of assessment, DBE workbooks, ATPs and internal reading policies available, there was consensus among all of the participants that the CAPS document was the primary policy that guided the teaching of reading in the Foundation Phase.

The following extract represents the point of view of the educators:

'I think only CAPS, but there are other documents like readers, big books and ATPs that we must have and also follow what the subject advisors give to us.' (School A, P5)
Another Grade 1 educator said:

'I struggle to manage all the assessments, documents and reports. The administrative part of teaching is killing me. I sometimes feel overwhelmed and hardly have time to support learners who need support.' (School C, P7)

\section{Weaknesses within the Curriculum and Assessment Policy Statement document}

The document analyses and interviews exposed that the CAPS EHL document (DBE 2011) lacks explicit and systematic guidance of the 'how' to teach reading in the Foundation Phase classroom. The CAPS EHL is explicit about the 'what' of teaching reading, for example the time allocation, activities like shared reading, independent reading, group-guided reading and paired reading. However, the participants agreed that the CAPS EHL document lacks explicit information on the implementation of the different reading strategies. They responded as follows:

'There is no clear guidance on how to implement reading, I follow my own methods and hope that it is on the correct path.' (School A, P2)

The Grade 2 educator stated that:

'There are too many methods in the CAPS document and this makes us confused about what to teach. The methods are there but not clear on how to use the methods.' (School B, P1)

It is evident from the extracts that the CAPS document, as the main policy document guiding reading, lacks proper guidance on 'how' to implement the actual teaching of reading. The educators made use of their own methods and this showed some differences and inconsistencies in the approach to the teaching of reading. All participants mentioned that CAPS EHL lacks explicit guidelines on how to teach reading. However, the educators in School A did not have problems with interpreting and implementing the CAPS EHL document in their classrooms, while School B and School C educators struggled to interpret and implement the CAPS document. However, there are two essential issues in the case of the three schools studied: on the one hand, there was the general observation that the CAPS document lacked clarity on 'how' to interpret and implement the policy, which was acknowledged by all the educators across the three schools. This is in line with Ekpiken and Francis (2015) who observed that most of the problems and crises with education are issues with the policy itself and the interpretation and implementation thereof. This confirms that the CAPS EHL document lacks guidance on methods and strategies to teach reading. The CAPS EHL document provides the components of reading and assessment, but no methodology on 'how' to use these for teaching reading. This makes it difficult for teachers to translate content into practice. Haris and Ghazalie (2016) note that to achieve success, the curriculum must be interpreted and implemented appropriately to ensure that learners understand and master a lesson. This will result in changed behaviour, improved effectiveness, quality education and the promotion of learners. Arguably, it is difficult for learners to understand the lesson content when educators themselves do not understand the policy content and implementation thereof (Haris \& Ghazalie 2016). 


\section{Analysis and interpretation of educators' English home language files}

All the schools had subject files for EHL, which included planned reading activities from Grade 1 to Grade 3. A detailed analysis of the educators' home language files provided information about each school's internal policies, the levels of planning involved in teaching reading, as well as assessment practices.

These files should also entail the schools' internal policies. An interesting observation was that the participants from School A all contributed to drawing up internal school policies like subject policies and Foundation Phase policies that are aligned with the CAPS documents for different subjects. The educators from School A collaborated to discuss the various CAPS documents and then drafted internally to assist and guide them with implementation. The HoD from School A made sure that educators use the CAPS document to guide their teaching of reading and that all the supplementary documents stipulated by the subject advisors are implemented, even if they were not mentioned in the CAPS document, and also used an internal reading policy. School B and School C did not make use of any internal policies.

The Foundation Phase educators from School A had an extra file for the planning of that week. All the educators did weekly planning with examples of the work that should be done for that week, including homework. These files are submitted to the principal every Monday for moderation:

'We submit every Monday our weekly prep to the principal, he checks and signs it, there must be examples of the weeks' worksheets and also homework included.' (School A, P3)

\section{The HoD commented that:}

'Weekly planning must be done according to the CAPS document, and this is where the educators interpret and implement the CAPS document into their daily teaching and then send to the principal to be signed; if there is no planning, how can the educator teach and do not have all relevant resources and copies ready for that period?' (School A, P5)

The educators from School B did their planning to the best of their knowledge and they sent it to another educator to sign the plan, which indicates a level of initiative in the absence of a HoD. Although the educators may not have the right knowledge to provide guidance, signing each other's work suggests a certain level of quality assurance and a step towards making sure that the work was covered as stipulated in the CAPS document. However, the absence of managerial support added a significant challenge to the implementation of the reading policies.

The Foundation Phase educators from School C did weekly planning according to the CAPS document. Examples of the work for that current week were included. There was no evidence that any person signed the weekly preparation:

'I just do my preparation according to the CAPS document and then get worksheets and resources according to that.' (School C, P3)
According to the CAPS document, educators must use informal and formal assessments. The educators made use of both baseline and continual assessment, using the assessment strategies prescribed by the CAPS document, for example oral assessment, reading and written tasks.

Before the educator from School A can do any assessment activity, the HoD has to moderate it to see if the task fits the ATPs and curriculum coverage. The educators complained that oral (speaking) and reading was taking very long and there was not enough time to do it properly. They paid more attention to the writing part of the assessment:

'Assessment is divided into different parts like first sounds, reading (individual reading and group-guided reading) and lastly, the written part, but oral and reading take very long because it is with each learner individually.' (School A, P2)

There was no moderation at School B because there was no HoD. The educators mentioned in the interviews that reading and oral take much time and there was not enough time to use all the different assessment strategies.

'Oral and reading are a problem because it takes much time to complete it, and you only work with one child at a time.' (School B, P4)

There was no pre- and post-moderation in School C because there was no HoD. Assessment guides the educator to see what level the learners in the class are at and what they grasp so that the things they struggle with can be revised.

\section{Interpretation of the Curriculum and Assessment Policy Statement document}

The participants did not complain much about the interpretation of the CAPS documents in connection with reading. However, they complained about the lack of clarity in the CAPS EHL document on how to teach reading, as this influences their daily teaching activities:

'If the authority "up there" must come to our level themselves and interpret and implement all their prescriptions, they will realise that it is impossible.' (School C: P3)

'There is no clear methods or instructions on how to teach reading, it is like a "guessing game" and not sure if what I "guess" is correct.' (School A, P3)

The interpretation of the CAPS document determines largely how policies are implemented in the classroom. Research (Dorner 2012; Dunn 2010) indicates that the implementation of policies relies on the interpretation of the policy. According to Dunn (2010), a key aim of the curriculum is to provide more specific guidance for educators to implement and interpret the policy. However, Dunn highlights a number of the terms in the CAPS document that need to be clarified to enhance the educators' understanding. As early as 2005, the Wits Education Policy Unit commented that educators make mistakes with the concepts in their lesson plans because the educators lacked understanding and were in need of support and training. The educators in this project reported that they did not receive baseline training at the beginning of the year, or during the year. Making sense of the curriculum before being able to implement it is important. 
Colebatch (2014) explains that the sense-making theory implies that people should make sense of different concepts and knowledge before they will be able to implement new knowledge. In addition, how people understand policies is influenced by how they understand the different interpretations, professional training, institutional positions, values, experiences and how they 'make sense' of the policies. Thus, if educators cannot make sense of the policy, they will not be able to implement it.

\section{Theme 2: Implementation of policies and support documents}

Since theme 1 indicated the limitations of the CAPF EHL document, as well as educators' inability to make sense of the policy documents, theme 2 focused on the implementation of the policy document, despite the two mentioned factors.

\section{Skills and knowledge educators need to implement reading policies}

The findings indicated that educators needed skills and knowledge to implement reading policies and other supporting documents. Although the educators tried their best, they, as well as the HoDs, indicated that they needed professional development to support them with the implementation of the policies and support documents:

'The department must arrange in-depth workshops focus on reading, that the HoDs can train the educators and assist them when there were problems and also can send a whole class to the next grade to know that all of the learners can read on an appropriate level.' (School A, P5)

'Yes, I try my utter best, I know like the resources we lack and we can make a plan to make it, but there is no time.' (School A, P2)

'Yes, I think I have, but training would assist in developing myself to be more skilled in reading. We maybe have once a year of training on reading.' (School A, P4)

\section{Teaching methods and strategies educators use to teach reading}

The participants made use of different techniques, tools and strategies that are suitable for teaching reading as prescribed by the CAPS document. In School A, the class observation showed that the three Foundation Phase educators made use of the CAPS document and the DBE workbook. At School $B$ and School C, the educators made use of shared reading and individual reading during class observation, no groupguided reading or paired reading.

With regard to LTSM, most participants stated that they make use of pictures, flashcards of sight words, which are later used on the wall. The methods that the educators used were in line with the CAPS document because the CAPS document lacks explicit methodology on the 'how', according to the interviews.

'The CAPS document is the most frustrating policy ever, we do not have a work programme to teach and find better ways to teach the learners. We have received no training at all for reading, just overall training for all four subjects in the Foundation Phase.' (School A, P4)
'Teaching aids will assist with teaching reading, most educators do the lecturing methods to the little ones, they must refrain from that and use a methodology that will assist them, but the CAPS document is silent as far as methodology is concerned. Educators must try to unpack the content and to turn it into activities, classroom management is the main problem and this is a skill that educators lack.' (Subject advisor)

This suggests two issues: firstly, that the CAPS document lacks clarity in terms of the methodology to teach reading and, secondly, that educators are expected to interpret the content by themselves without explicit guidelines on how it should be done. Yet, in all the classrooms, the participants only made use of direct teaching methods with learners seated in pairs at a table facing the chalkboard. The seating arrangement and the size of classrooms constrained the educators to the one teaching method that they were observed using. The learners could not work in groups because of how the educator arranged the classroom, as well as the overcrowding.

\section{Conclusion}

The educational achievement of learners in South African schools is alarming and educators' inability to interpret and implement the reading policies is often blamed (DBE 2008). Thus, the motivation for this article was to report how educators interpret and implement the CAPS, assessment programmes and ATPs, to plan the teaching of reading in the Foundation Phase.

The findings indicated that educators mainly use the CAPS document and DBE workbooks to teach reading in the Foundation Phase. A weakness about the CAPS document revealed during the document analysis is that CAPS is clear about 'what' to teach, but lacks clear, directive guidelines on 'how' to teach reading. Therefore, educators are not sure how to interpret the CAPS document as part of their daily teaching. Although the CAPS document mentions group-guided reading, paired reading, shared reading and individual reading, the findings revealed that independent reading and shared reading in class occurs most of the time, yet group-guided reading and paired reading do not take place. A possible reason might be overcrowded, under-resourced classrooms.

Based on these findings, and in line with Ndou (2015), who comments that educators can implement the policies in any way they want to, we want to suggest that training for in-service teachers should focus on exactly how reading should be taught in the Foundation Phase. The ATPs provide detailed information about the assessment tasks, yet this needs to be supplemented by step-by-step guidance on exactly how the five components should be taught in each grade. Educators need to have thorough, research-based knowledge on how to teach reading, but also on how to support learners who do not reach their benchmarks in reading. Therefore, we recommend that the onset of in-service teacher development should be a needs analysis of the educators because this project indicated that teachers do not know how to interpret the policy documents in the best interest of Foundation Phase learners. 


\section{Acknowledgements}

First of all, with enormous pleasure, I express my deep indebtedness to my supervisor and co-supervisor, mentors and friends, Prof. Pontso Moorosi and Dr Elsabé Wessels. Their exceptional guidance, support, friendship and enthusiasm were critical for my studies and it will inspire me throughout my career. They both taught me consciously and unconsciously, and the joy and enthusiasm they have for research was contagious and motivational. I would like to thank my mother and father, Ann and Bushy Fourie. Both have instilled many admirable qualities in me and provided me with a good foundation in life. I would like to thank all my friends and family, especially my parents-in-law, Marthie and Lood Marais, for all their help, love and encouragement. I must acknowledge, with tremendous gratitude and deep thanks, my loving, supportive, encouraging and patient husband, Chris Marais. He has been there for me in the most difficult periods, always making them bearable. With his love, patience, support and unwavering belief in me, I have been able to complete this journey. I thank the National Teaching Awards of 2013 for my bursary from ETDP SETA towards further study. This motivated me to enrol for my master's degree. Thank you for this opportunity. I also thank my colleagues at Lichtenburg Primary School for their support and understanding during this time. Above all, I owe all thanks to the Almighty God for granting me the wisdom, health and strength to undertake this study and enabling me to complete it.

\section{Competing interests}

The authors have declared that no competing interest exists.

\section{Author's contributions}

E.W. acted as supervisor with A-M.M.'s Masters degree and gave input as co-author while A-M.M. wrote most of the article.

\section{Funding information}

This research received no specific grant from any funding agency in the public, commercial or not-for-profit sectors.

\section{Data availability statement}

The authors confirm that the data supporting the findings of this study are available within the article.

\section{Disclaimer}

The view and opinion expressed in this article is those of the author and do not necessarily reflect the official policy or position of any affiliated agency of the author.

\section{References}

Adam, A., 2014, 'The development of a school-wide progress monitoring assessment system for early literacy skills', PhD thesis, North-West University, Potchefstroom.

Bhaskar, R., 1978, 'On the possibility of social scientific knowledge and the limits of naturalism', Journal for the Theory of Social Behaviour 8(1), 1-28.
Boughey, C., 2012, 'The significance of structure, culture and agency in efforts to support and develop student learning at South African universities', in R. Vithal (ed.), Access and success in higher education, Dunpath, Cape Town.

Bourne, M., 2003, Factors that play a role in 'management through measures', MCB UP, Bingley.

Bretag, T. (ed.), 2016, Handbook of academic integrity, Springer, Singapore.

Buhlungu, S., Daniel, J., Southall, R. \& Lutchman, J., 2007, State of the Nation, South Africa 2007, HSRC Press, Cape Town.

Bush, T., 2012, Authenticity in research: Reliability, validity and triangulation SAGÉ Publications Ltd, Thousand Oaks, CA.

Coburn, C.E., 2001, 'Collective sensemaking about reading: How teachers mediate reading policy in their professional communities', Educational evaluation and policy analysis 23(2), 145-170. https://doi.org/10.3102/01623737023002145 Public Administration 72(3), 349-356. https://doi.org/10.1111/1467-8500.12088

Creswell, J.W., 2013, Qualitative inquiry and research design: Choosing among five approaches, Sage, Thousand Oaks, CA.

Creswell, J.W., 2014, Research design: Qualitative, quantitative and mixed methods approaches, Sage, Thousand Oaks, CA.

Cross, A.F. \& Conn-Powers, M., 2014, Making the intentional decision to use an effective curriculum to promote children's learning, Pearson Education, Upper Saddle River, NJ.

De Vos, A.S., Strydom, H., Fouché, C.B. \& Delport, C.S.L., 2006, Research at grass roots for the social sciences and human service professions, 3rd edn., Van Schaik, Pretoria.

Department of Basic Education (DBE), 2008, 'Foundations for learning campaign', Notice 306 of 2008, Government Gazette 30880.

Department of Basic Education (DBE), 2011, Curriculum and Assessment Policy Statements (CAPS) - Home language, Government Printing Works, Cape Town.

Department of Basic Education (DBE), 2013, National Reading Programme for Grades $R$ to 3 - Reading Norms, Publishing date: 14 May 2013.

Dorner, L.M., 2012, 'The Life course and sense-making: Immigrant families' journeys toward, understanding educational policies and choosing bilingual programs, American Educational Research Journal 49(3), 466. https://doi.org/10.3102/0002831211415089

Dunn, K., 2010, Submission on the National Curriculum and Assessment Policy Statements for all subject listed in the National Curriculum Statements Grades, Catholic Institute of Education, Johannesburg.

Ekpiken, W.E. \& Francis, I., 2015, 'Politics of leadership and implementation of educational policies and programmes of tertiary institutions in Cross River State, Nigeria', Journal of Education and Practice 35(6), 37-47.

Harris, A. \& Ghazali, M.I., 2016, 'Implementation of teacher learning in physical education curriculum at the junior school in Makassar, Indonesia', Journal of Physical Education and Sport 110, 683-687.

Huberman, A.M. \& Miles, M.B., 2002, 'Introduction', in A.M. Huberman \& M.B. Miles (eds.), The qualitative researcher's companion, pp. 37-64, Sage, Thousand Oaks, CA.

Jackson, G., 2003, 'A comparative case study of strategies used by Grade 1 teachers who teach through the medium of English', master's thesis, Rhodes University, Grahamstown.

Maree, K. (ed.), 2009, First steps in research, Van Schaik, Pretoria.

McKeown, M.G. \& Beck, I.L., 2006, 'Encouraging young children's language interactions with stories' in D.K. Dickinson \& S.B. Neuman (eds.), Handbook of early literacy research, vol. 2., pp. 281-294, Guilford, New York.

McMillan, J.H. \& Schumacher, S., 2010, Research in education: A conceptual introduction, 7th edn., Pearson, New York, NY.

Mouton, J., 2003, How to succeed in your master's and doctoral studies. A South African quide and resource book, Van Schaik, Pretoria.

National Reading Panel (NRP), 2000, Teaching children to read: An evidence-based assessment of the scientific research literature on reading and its implication for reading instruction, viewed 10 November 2008, from http://www.nifl.gov.

Ndou, N., 2015, 'Managing the implementation of education policies for quality education in public schools of Limpopo Province', PhD thesis, University of South Africa, Pretoria.

Nehal, M., 2013, A study of reading assessment in the Grade 4 classrooms, University of KwaZulu-Natal, Durban.

Pandor, N., 2008, Address by the Minister of Education, Naledi Pandor, at the Foundation Phase Conference, 30 September 2008, viewed 03 March 2009, from http://www.info.gov.za/speeches.htm.

Root, D.A., 2013, 'Purpose, policy, and possibilities: Social studies teachers' sensemaking of curriculum', PhD thesis, University of Texas, San Antonio, TX.

Van der Berg, S., 2015, 'What the Annual National Assessments can tell us about learning deficits over the education system and the school career', South African Journa of Childhood Education 5(2), 28-43. https://doi.org/10.4102/sajce.v5i2.381

Van der Merwe, Z.E., 2011, 'An analysis of what and how reading literacy components are included and taught within a Foundation Phase teacher preparation programme', PhD thesis, North-West University, Potchefstroom.

Wessels, E., 2011, 'Teacher knowledge and implementation of phonological awareness in Grade R', PhD thesis, North-West University, Potchefstroom.

Wits Education Policy Unit, 2005, The state of teacher professionalism in South Africa, South African Council for Educators (SACE), Johannesburg.

Wium, A. \& Louw, B., 2011, 'Teacher support - An exploration of how foundation-phase teachers facilitate language skills', Educational Journal (SAJCD) 58(2), 14-17.

Wood, L., 2019, Participatory action learning and action research: Theory, practice and process, Routledge, London.

Wood, L., 2020, Participatory action learning and action research, Routledge, London. 